\title{
Correlation between the proportion of healthy mammary tissue versus tumor size in breast-conserving surgeries
}

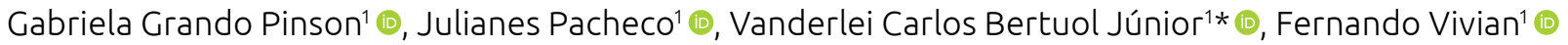

\section{ABSTRACT}

Objective: To evaluate the proportion of excised healthy tissue in breast-conserving surgeries and to identify possible tendency toward excision in healthy tissue beyond the ideal for oncological safety. Methods: Data from patients who underwent breastconserving surgery at the Hospital Geral de Caxias do Sul from January 2010 to December 2016 were analyzed. For statistical purposes, means, standard deviations, Student's t-test, and linear regression were used for numerical variables. Risk estimate by odds ratio (OR) was performed through logistic regression with $95 \% \mathrm{Cl}$. A significance level (alpha) of $5 \%$ was adopted. Results: A total of 124 cases were analyzed. The mean tumor size observed by ultrasonography was $1.7 \pm 0.95 \mathrm{~cm}$. The tumor size was $1.9 \pm 1.12 \mathrm{~cm}$. The mean size of the resected surgical specimens was $7.8 \pm 3.4 \mathrm{~cm}$. When comparing the tumor size in the anatomopathological examination and the size in ultrasonography, the mean differences accounted for $0.6 \mathrm{~cm}(95 \% \mathrm{Cl}-0.10-$ $0.44 ; p=0.2)$. Conversely, the difference in the size of the total surgical specimen versus tumor size in the anatomopathological examination was $5.8 \mathrm{~cm}(95 \% \mathrm{Cl} 5.2-6.5 ; \mathrm{p}<0.001)$. There was no statistical difference regarding the tumor location nor size of the surgical specimen. Conclusion: It was observed that there is a tendency toward excising a large amount of healthy tissue in breastconserving surgeries far beyond what is recommended in order to consider the oncological safety of excised margins.

KEYWORDS: mastectomy, segmental; margins of excision; breast neoplasms; treatment outcome; esthetics.

\section{INTRODUCTION}

Breast cancer is the tumor that most affects women worldwide. In Brazil, breast cancer mortality rates remain high, probably because the disease is still diagnosed in advanced stages. Population screening programs enabled more diagnoses of early-stage injuries, reducing death cases and promoting less aggressive surgeries ${ }^{1}$. The José Alencar Gomes da Silva Brazilian National Cancer Institute (Instituto Nacional de Câncer - INCA) estimated 59,700 new cases of breast cancer in Brazil in 2018². In Caxias do Sul, in the state of Rio Grande do Sul, 46 cases of death from breast cancer were identified in $2016^{3}$.

Surgical treatment of breast cancer has undergone significant changes in recent decades, and breast-conserving surgery is the standard treatment for the early stages of the disease nowadays ${ }^{4}$.
The radical mastectomy technique and its corresponding lymphatic drainage have been abandoned. The old Halstedian paradigm had been overcome, and conservative treatments, both for the excision of breast tissue and for the surgical approach of the armpit, have been increasingly employed ${ }^{5,6}$.

The theory proposed by Bernard Fisher, which defines breast cancer as a systemic disease, was the basis for the development of breast-conserving surgery, providing a new and much-less aggressive perspective to surgical therapy ${ }^{7-9}$.

Veronesi, author of the renowned Milan I study, conducted between 1973 and 1980, analyzed 701 cases of early-stage breast cancer and randomized a group to undergo breast-conserving surgery with radiotherapy and another group with radical mastectomy ${ }^{10}$. After 20 years of follow-up, the author observed that both 
groups obtained the same long-term survival rates. This study revolutionized breast cancer treatment, making breast-conserving surgery a treatment chosen for early-stage cases ${ }^{11}$.

Nowadays, most patients in stages I and II of the disease are candidates for breast-conserving treatment, which consists of undergoing surgery with partial excision of the mammary gland (sectionectomy or quadrantectomy) followed by radiotherapy ${ }^{1}$. For this surgical decision, tumor size is not an exclusive limiting factor of conservative surgery. The tumor-to-breast volume ratio is the most important anatomical factor. Thus, breast-conserving surgery must always be the first option, provided that there are no contraindications to the procedure and that the tumor-tobreast volume ratio allows a surgical excision with satisfactory cosmetic outcome, according to oncological surgery concepts ${ }^{12}$.

Therefore, it is established that the aim of breast-conserving surgery is to completely remove the tumor with free margins, obtaining a good cosmetic result, but without compromising local recurrence rates ${ }^{1}$.

Prospective, randomized clinical trials have shown that there is no significant difference in distant disease-free survival or overall survival between patients treated with mastectomy and those treated with breast-conserving surgery and radiotherapy. This reinforces the indication of breast-conserving surgery as the best cosmetic alternative for most patients, since it provides the same cure rates without the aggressiveness and mutilation caused by mastectomy ${ }^{9,11}$. However, 4 to $20 \%$ of patients with early-stage breast cancer have local recurrence $e^{13}$.

The lack of adjuvant radiotherapy and positive surgical margins was associated with an increase in this recurrence ${ }^{13,14}$. In addition, it is known that local recurrence increases the risk of distant recurrence ${ }^{15,16}$. Compromised surgical margin is the most common indication of reexcision after breast-conserving surgery, and this approach can lead to worse cosmetic results, increased risk of infection, higher costs, and delay in early adjuvant treatment ${ }^{1}$.

There is an intense debate about surgical margins, although the 2010 International Consensus defines positive margin as ink on microscopic tumors in cases of invasive carcinomas and a 2-mm margin for carcinoma in situ ${ }^{16,17}$.

Factors, such as tumor biology and the availability of effective systemic therapy, are as important as the margin of microscopic residual disease in determining local control. The standard definition of negative margin as no ink on the tumor has the clear potential to decrease the indication for surgical reexcision, in addition to avoiding large resections that often require additional remodeling surgery of the affected breast and even of the contralateral breast for symmetry purposes ${ }^{17,18}$.

Over the years, the idea that the lower the volume of excised healthy tissue, the greater the probability of incomplete removal of the neoplasm has been promoted. Likewise, there would be a greater probability of local recurrence due to the growth of the remaining neoplasm. However, the higher the volume of excised breast tissue, the lower the chances of obtaining more satisfactory cosmetic results ${ }^{12}$.

Waljee et al. conducted a study in which they evaluated the aesthetic effect perceived by patients after breast-conserving surgery, and demonstrated that large asymmetries were correlated with depressive symptoms and worsening in the psychosocial functioning and quality of life of these women ${ }^{19}$.

Thus, considering the importance of the theme, the present study aimed to identify possible tendencies toward excision in healthy tissue beyond the ideal for oncological safety. The results observed here can be used to produce recommendations regarding the volume of tissue to be excised, aiming at cosmesis and aesthetics without impairing the oncological conduct for breast surgeries.

\section{METHODS}

This is a cross-sectional and retrospective study conducted at the Mastology Center of Hospital Geral de Caxias do Sul, in the state of Rio Grande do Sul, Brazil. The medical records of all patients who underwent breast-conserving surgery at the institution, from January 2010 to December 2016, were analyzed.

Eligibility criteria were considered for patients who underwent breast-conserving surgery (sectionectomy or quadrantectomy) and who had a diagnosis of cancer at the time of surgery or cases already confirmed prior to the procedure (prior biopsy).

Data on incomplete or dubious medical records, multicentric/ multifocal tumors, and patients submitted to surgical reintervention to enlarge margins were deemed reasons for exclusion from the study.

Data were compiled and evaluated after surveying medical records by research members. The following categories were analyzed: age; menopausal status; tumor size on ultrasonography; tumor size on anatomopathological examination; size of the excised surgical specimen; excised healthy tissue; free or not surgical margin; number of compromised axillary lymph nodes; chemotherapy; tumor location; and histological and molecular characteristics.

Due to the heterogeneity of information in the medical records, the tumor size for the anteroposterior diameter in ultrasound and anatomopathological examination and the size of the excised tissue were considered for comparison purposes.

For patients undergoing neoadjuvant chemotherapy, the residual tumor size after chemotherapy treatment was taken into account.

In the analysis of surgical margin, the disease-free surgical margin was established as no ink on the tumor in cases of invasive tumors and margins greater than $2 \mathrm{~mm}$ in cases of tumors in situ.

\section{Data analysis}


For statistical purposes, means, standard deviations, Student's t-test, and linear regression for numerical variables were used. A risk estimate was carried out by odds ratio(OR) through logistic regression with a $95 \%$ confidence interval (95\%CI). Significance level (alpha) of $5 \%$ was adopted.

The database was submitted to a double-entry process with inconsistency processing. Moreover, multivariate backward linear logistic regression was used, associating the new variable with those previously reported. P-value $<0.05$ was deemed statistically significant. Analyses were performed using R 3.1.1 for Windows (R-Cran project), with the MASS package for Windows.

The study was submitted to and approved by the Research Ethics Committee of Universidade de Caxias do Sul (UCS).

\section{RESULTS}

Of the total of 194 breast-conserving surgeries performed from January 2010 to December 2016, and according to the inclusion and exclusion criteria, 124 patients remained in the study. The other cases were excluded due to reexcisions, subsequent surgeries related to margin enlargement and multicentric or multifocal tumors, and those related to incomplete hospital data.

Table 1 summarizes the characteristics and results obtained in the present study. In the study group, $56.9 \pm 11.7$ was the mean

Table 1. Clinical and demographic characteristics of patients included in the study $(n=124)$.

\begin{tabular}{|c|c|}
\hline Characteristic & Value (\%) \\
\hline Menopausal status & $\begin{array}{l}\text { Premenopausal: } 33 \text { (26.6\%) } \\
\text { Postmenopausal: } 91 \text { (73.4\%) }\end{array}$ \\
\hline Axillary status & $\begin{array}{l}\text { Negative: } 92(74.2 \%) \\
\text { 1-3 positive: } 24(19.3 \%) \\
\text { > } 4 \text { positive: } 8(6.5 \%)\end{array}$ \\
\hline Histological type & $\begin{array}{c}\text { NST: } 70 \text { cases }(56.5 \%) \\
\text { NST + DICS: } 18 \text { cases }(14.5 \%) \\
\text { Special subtypes: } 14(11.3 \%) \\
\text { DCIS: } 13(10.5 \%) \\
\text { ILC: } 5(4 \%) \\
\text { Other types: } 4(3.2 \%)\end{array}$ \\
\hline Immunohistochemistry & $\begin{array}{c}\text { Luminal A } 56(45 \%) \\
\text { Luminal B } 48(39 \%) \\
\text { HER2 } 11(8.8 \%) \\
\text { Triple-negative } 7(5.6 \%) \\
\text { No tests } 2(1.6 \%)\end{array}$ \\
\hline Characteristic & Value (mean with SD) \\
\hline Age & $56.9 \pm 11.7$ years \\
\hline Tumor size in US & $1.7 \pm 0.95 \mathrm{~cm}$ \\
\hline Tumor size in AP & $1.9 \pm 1.12 \mathrm{~cm}$ \\
\hline Size of the surgical specimen & $7.8 \pm 3.4 \mathrm{~cm}$ \\
\hline
\end{tabular}

US: ultrasound; AP: anatomopathological examination; NST: invasive ductal carcinoma (of no special type); DCIS: ductal carcinoma in situ; ILC: invasive lobular carcinoma; HER2: human epidermal growth factor receptor 2; SD: standard deviation. age in years. Considering menopausal status, 33 patients (26.6\%) accounted for premenopausal status, and 91 of them $(73.4 \%)$ accounted for postmenopausal status at the time of diagnosis.

Regarding the axillary status, 92 patients $(74.2 \%)$ had negative axillarylymph nodes, 24 (19.3\%) had 1-3 lymph nodes compromised by neoplasia, and $8(6.5 \%)$ had more than four affected lymph nodes.

It was identified that 59 patients did not undergo chemotherapy. Of the 65 patients who did it, 48 were adjuvant and 17 were neoadjuvant.

Regarding the pathological characteristics of the tumors, 70 cases (56.5\%) were of no special type (invasive ductal); 18 (14.5\%) had invasive ductal carcinoma and concomitant in situ; 14 cases (11.3\%) were of special subtypes (e.g., tubular, medullary, mucinous, papillary, etc.); 13 (10.5\%), ductal carcinoma in situ; and 5 cases (4\%) of invasive lobular carcinoma. Four (3.2\%) tumors exhibited histological types other than those aforementioned.

As for molecular classification by immunohistochemistry, 56 tumors (45\%) were of the type Luminal A; 48 (39\%), Luminal B; 11 (8.8\%), human epidermal growth factor receptor 2 (HER2); and 7 (5.6\%), triple-negative breast cancer. In two cases, immunohistochemistry was not performed because they were nonepithelial tumors (1.6\%).

In Table 2 and Graph 1, one may observe the distribution of tumors regarding the location in the breast and the mean of excised tissue. There was no statistical difference regarding tumor location and neither concerning the size of excised tissue in the surgical specimen.

The mean tumor size observed by ultrasonography was $1.7 \pm 0.95 \mathrm{~cm}$. The tumor size in the anatomopathological examination was $1.9 \pm 1.12 \mathrm{~cm}$. Conversely, the mean size of the excised surgical specimens was $7.8 \pm 3.4 \mathrm{~cm}$.

Table 3 and Graph 2 show the amount of excised tissue according to tumor size (in the anatomopathological examination). When comparing groups 1,2 , and 3 with group 4 , there was an increase in the resected tissue in group 4 with statistical difference $(p<0.01)$.

When comparing the tumor size in the anatomopathological examination and the size in ultrasonography, the mean differences accounted for $0.6 \mathrm{~cm}(95 \% \mathrm{CI}-0.10-0.44$; $\mathrm{p}=0.2)$.

Table 2. Location of tumors and mean excised tissue.

\begin{tabular}{l|c|c|c} 
Quadrants & $\mathbf{N}(\%)$ & Excised size & $95 \% \mathrm{Cl}$ \\
UOQ + JUQ & $70(56.5)$ & $8.1 \mathrm{~cm}$ & $7.5-9$ \\
\hline LOQ + JOQ & $21(16.9)$ & $6.7 \mathrm{~cm}$ & $5.5-8.2$ \\
\hline UIQ + JIQ & $13(10.5)$ & $6.3 \mathrm{~cm}$ & $4.5-8.2$ \\
\hline LIQ + JLQ & $17(13.7)$ & $8.4 \mathrm{~cm}$ & $7-10.2$ \\
\hline RA & $3(2.4)$ & $5.6 \mathrm{~cm}$ & $1.8-9.5$ \\
\hline
\end{tabular}

$\mathrm{UOQ}+$ JUQ: upper outer quadrant + junction of the upper quadrants; LOQ + JOQ: lower outer quadrant + junction of the outer quadrants; UIQ + JIQ: upper inner quadrant + junction of the inner quadrants; LIQ + JLQ: lower inner quadrant + junction of the lower quadrants; RA: retroareolar region; 95\% Cl: 95\% confidence interval. 
On the other hand, the ratio between the size of the total surgical specimen and the tumor size in the anatomopathological examination accounted for $5.8 \mathrm{~cm}$ (95\%CI 5.2-6.5; p < 0.001).

In all cases, free surgical margins were obtained, as established by the literature.

\section{DISCUSSION}

Breast cancer is relatively rare before the age of 35, and its incidence progressively increases above this age, especially after 50 years of age ${ }^{2}$. The age group of patients in our study ranged from 27 to 77 years (mean of $56.7 \pm 11.7$ years), and most $(73.4 \%$ ) were postmenopausal.

The development and evolution of the sentinel-lymph-node biopsy have positively affected the treatment of early-stage breast cancer. This procedure provides accurate diagnosis and prognostic information on patients with clinically negative lymph nodes and consists of a primary tool to guide surgical and adjuvant treatment. In many cases, sentinel-lymph-node biopsy has

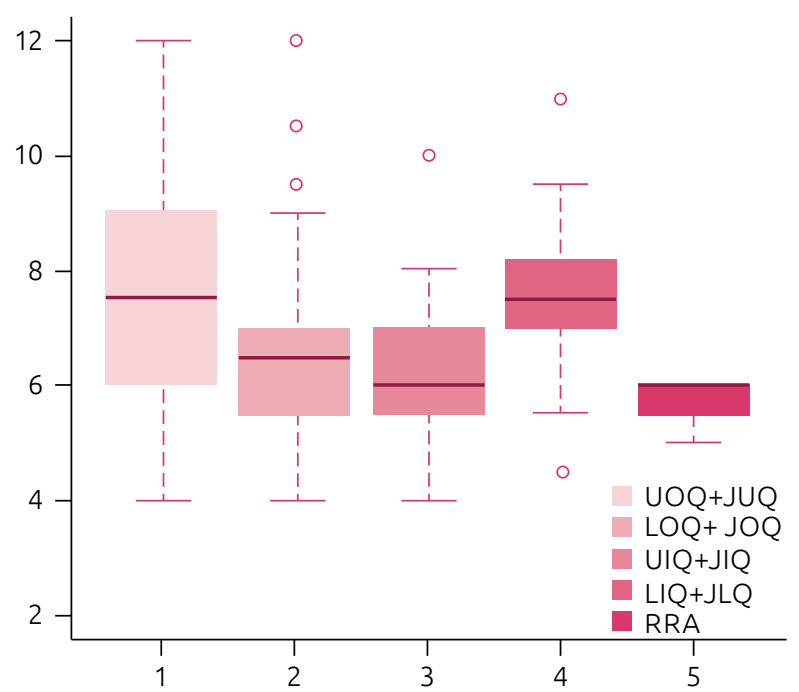

Graphic 1. Size of the surgical specimen versus tumor location. UOQ + JUQ: upper outer quadrant + junction of the upper quadrants; LOQ + JOQ: lower outer quadrant + junction of the outer quadrants; UIQ + JIQ: upper inner quadrant + junction of the inner quadrants; LIQ + JLQ: lower inner quadrant + junction of the lower quadrants; RA: retroareolar region.

Table 3. Tumor size versus excised tissue size.

\begin{tabular}{l|c|c} 
Group & Tumor size & Excised size (mean) \\
\hline 1 & $<1 \mathrm{~cm}$ & $7.2 \mathrm{~cm} \pm 0.55$ \\
\hline 2 & 1 to $2 \mathrm{~cm}$ & $6.94 \mathrm{~cm} \pm 0.71$ \\
\hline 3 & $>2-3 \mathrm{~cm}$ & $7.83 \mathrm{~cm} \pm 0.81$ \\
\hline 4 & $>3 \mathrm{~cm}$ & $11.42 \mathrm{~cm} \pm 1.0$ \\
\hline
\end{tabular}

replaced axillary dissection, and patients were spared of lymphedema and additional morbidity attributed to this procedure, thus improving their quality of life ${ }^{20}$.

In the present research, 92 patients $(74.2 \%)$ had negative axillary lymph nodes; 24 (19.3\%) had 1-3 lymph nodes compromised by neoplasia; and only 8 (6.5\%) had more than four affected lymph nodes. Since this study only analyzed breast-conserving surgeries and, therefore, patients with early-stage cancer, most patients did not present lymph node metastases.

Veronesi et al. analyzed patients with tumors $<2$-cm who were submitted to sentinel-lymph-node investigation, and found that $65 \%$ of them presented negative lymph nodes at the time of the surgery ${ }^{21}$.

A Korean study, whose authors analyzed 945 patients with breast cancer in stages I and II, showed that the molecular subtype is a prognostic factor as important as the compromise of lymph nodes ${ }^{22}$. In this same study, the most frequent subtypes, in order, were Luminal A (41\%), Luminal B (29.1\%), triple-negative (21.6\%), and HER2 (8.3\%). In our study, Luminal A and Luminal $\mathrm{B}$ were also the majority, but there were more cases of HER2 than triple-negative.

Invasive ductal carcinoma of no special type is the most common histological type, corresponding to 40-75\% of breast carcinomas, depending on the series evaluated, and invasive lobular carcinoma accounts for 5-15\% of invasive carcinomas ${ }^{23}$. The findings of this research showed that the invasive ductal carcinoma of no special type corresponded to $56.5 \%$ of cases, and the invasive lobular corresponded to $4 \%$, corroborating data presented in other studies.

The authors identified 70 cases $(56.6 \%)$ of tumors located in the upper outer quadrant or junction of the upper quadrants, which are quadrants where there is a higher volume of breast

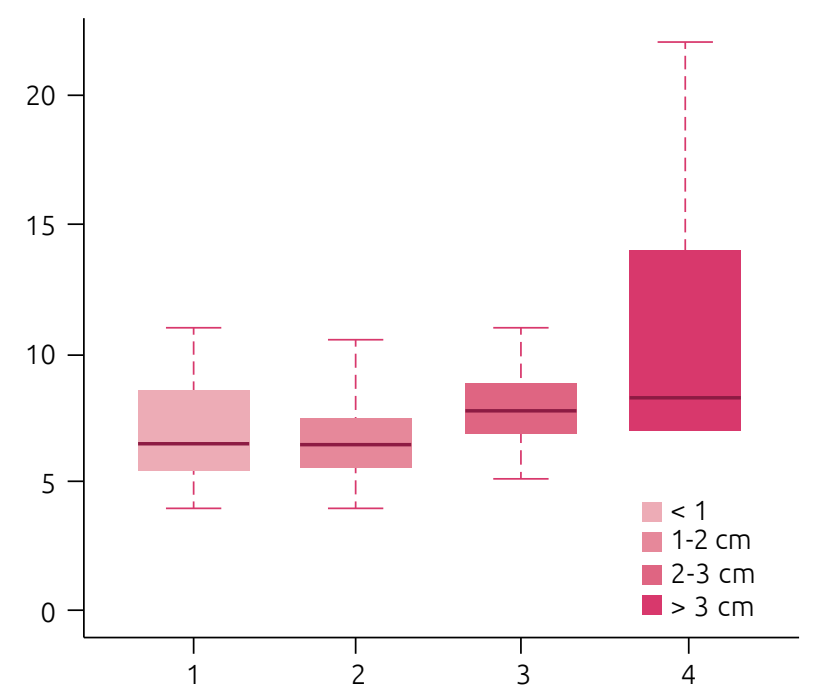

Graphic 2. Size of surgical specimen versus tumor size. 
tissue and, therefore, are more likely to develop the neoplasm. There was no statistical difference regarding tumor location and neither concerning the size of excised tissue in the surgical specimen.

The mean tumor size was $1.9 \pm 1.12 \mathrm{~cm}$, a result similar to that found in other studies whose authors analyzed patients with early-stage breast cancer ${ }^{24,25}$.

With the increased use of neoadjuvant chemotherapy and breast-conserving surgery, the accuracy of preoperative tumor size assessment has become important for assisting in the therapeutic decision. Tests such as ultrasound, mammography, and magnetic resonance imaging, can be used for this purpose. Studies have shown that ultrasound is better than mammography for estimating tumor size ${ }^{26}$. When comparing ultrasound and mammography with magnetic resonance imaging, the latter is the most accurate method ${ }^{27}$. When comparing tumor size in anatomopathological examinations and its size in ultrasonography, the mean difference of $0.6 \mathrm{~cm}(95 \% \mathrm{CI}-0.10-0.44 ; \mathrm{p}=0.2)$ was identified.

Authors of other studies have also observed differences, such as Shoma et al., who compared the evaluation of tumor size by physical examination, mammography, and ultrasound and found a mean difference of $3.2 \pm 0.4 \mathrm{~mm}^{28}$ in size between ultrasound and anatomopathological examination.

It is clearly perceived that larger tumors dictate techniques that ultimately excise a greater amount of healthy tissue. When comparing groups 1, 2, and 3 with group 4, there was an increase in the size of excised tissue in group 4, with statistical difference $(\mathrm{p}<0.01)$. This shows the clear tendency of surgeons for being more aggressive, even in conserving surgeries, when operating tumors whose mean diameter is greater than $3 \mathrm{~cm}$.

The tumor-to-breast volume ratio does not become an absolute contraindication to breast-conserving surgery, provided that it is possible to excise the tumor area, maintaining oncological safety, and causing no large asymme$\operatorname{tries}^{12}$. Taking this into consideration, patients with large tumors and small breasts are not likely to be submitted to breast-conserving surgery. Conversely, patients with more voluminous breasts consequently allow for greater tissue resection without major aesthetic impairments, which may justify our findings.

The difference in the size of the total surgical specimen and the tumor size in the anatomopathological examination accounted for $5.8 \mathrm{~cm}$ (95\%CI 5.2-6.5; $\mathrm{p}<0.001)$. When performing simple linear regression, it was observed that every $1 \mathrm{~cm}$ of tumor in the anatomopathological examination corresponds to $6.7 \mathrm{~cm}$ of surgical tissue.

This finding demonstrates that excessive and unnecessary healthy tissue is being excised in order to obtain a disease-free surgical margin. One possible reason for explaining excessive resection is the attempt to avoid subjecting the patient to a new surgical procedure to enlarge the margins, thus delaying the onset of adjuvant therapy.

The need to obtain disease-free surgical margins is due to the fact that this is the most important factor in reducing the risk of local recurrence ${ }^{29}$. It is known that $1 / 4$ of patients undergoing breast-conserving surgery will require a new surgical procedure for margin enlargement ${ }^{30}$. The use of frozen section histology assists in identifying margins compromised during the intraoperative period, avoiding excessive tissue excision or other surgery, providing more comfort and agility to the surgeons, since they will have information on enlargement of margins in appropriate time for doing it so, which also enhances the chances for surgeries seeking to conserve more healthy tissues.

Nevertheless, this evaluation technique is not a standard procedure in all services, and some authors suggest that the tool may alter the pathological staging and is contraindicated in some cases, such as in small tumors. In addition, the definition of complete excision of the tumor with safety margins is only provided after a histological study of the surgical specimen embedded in paraffin ${ }^{12}$.

Another reason that could explain excessive excision of healthy tissue is the fact that patients with large breasts have greater possibility of wide resection with minor aesthetic defects; however, the purpose of this study was not to evaluate the preoperative breast volume.

\section{CONCLUSION}

It was observed there is a tendency toward excising a large amount of healthy tissue in breast-conserving surgeries, far beyond what is recommended in order to consider the oncological safety of excised margins. The excessive excision of healthy tissue found in this study can bring severe deformities to the breast. An unfavorable aesthetic result may generate emotional impairment and compromise the patients' quality of life, thus opposing the main objective of breast-conserving surgery, which is to maintain cosmesis without harming the oncological conduct.

\section{AUTHORS' CONTRIBUTIONS}

G.P.: Conceptualization, Data curations, Formal analysis, Funding acquisition, Investigation, Methodology, Project administration, Resources, Software, Supervision, Validation, Visualization, Writing - original draft, Writing - review \& editing. F.V.: Conceptualization, Funding acquisition, Methodology, Project administration, Supervision, Validation, Writing - review \& editing. V. B.: Data curation, Investigation, Visualization.

J. P.: Data curation, Investigation, Visualization. 


\section{REFERENCES}

1. Silva JME, Marinho FMB, Tonellotto F, Giola SM, Monteiro SO, Bello MA, et al. Margens cirúrgicas no tratamento conservador do câncer de mama: revisão sistemática. 2014;24(3):70-5. http://dx.doi.org/10.5327/Z201400030003RBM

2. Instituto Nacional de Câncer José Alencar Gomes da Silva. Estimativas câncer de mama. Brasil: Ministerio da Saúde; 2016.

3. Caxias do Sul. Secretaria Municipal da Saúde. Óbitos por Neoplasias de Residentes de Caxias do Sul. Caxias do Sul: Secretaria Municipal da Saúde; 2016.

4. Luini A, Gatti G, Galimberti V, Zurrida S, Intra M, Gentilini O, et al. Conservative treatment of breast cancer: its evolution. Breast Cancer Res Treat. 2005;94(3):195-8. https://doi. org/10.1007/s10549-004-7376-0

5. Halsted WSI. The Results of Radical Operations for the Cure of Carcinoma of the Breast. Ann Surg. 1907;46(1):1-19. https:// dx.doi.org/10.1097\%2F00000658-190707000-00001

6. Halsted WSI. The Results of Operations for the Cure of Cancer of the Breast Performed at the Johns Hopkins Hospital from June, 1889, to January, 1894. Ann Surg. 1894;20(5):497-555. https://dx.doi.org/10.1097\%2F00000658-189407000-00075

7. Fisher B. Biological and clinical considerations regarding the use of surgery and chemotherapy in the treatment of primary breast cancer. Cancer. 1977;40(1 Supl.):574-87. https://doi.org/10.1002/1097-0142(197707)40:1+\%3C574::aidcncr2820400724\%3E3.0.co;2-o

8. Fisher B, Jeong JH, Anderson S, Bryant J, Fisher ER, Wolmark $\mathrm{N}$. Twenty-five-year follow-up of a randomized trial comparing radical mastectomy, total mastectomy, and total mastectomy followed by irradiation. N Engl J Med. 2002;347(8):567-75. https://doi.org/10.1056/NEJMoa020128

9. Fisher B, Anderson S, Bryant J, Margolese RG, Deutsch M, Fisher ER, et al. Twenty-year follow-up of a randomized trial comparing total mastectomy, lumpectomy, and lumpectomy plus irradiation for the treatment of invasive breast cancer. N Engl J Med. 2002;347(16):1233-41. https://doi.org/10.1056/NEJMoa022152

10. Veronesi U, Saccozzi R, Del Vecchio M, Banfi A, Clemente $\mathrm{C}$, De Lena $\mathrm{M}$, et al. Comparing radical mastectomy with quadrantectomy, axillary dissection, and radiotherapy in patients with small cancers of the breast. $\mathrm{N}$ Engl J Med. 1981;305(1):6-11. https://doi.org/10.1056/ NEJM198107023050102

11. Veronesi U, Cascinelli N, Mariani L, Greco M, Saccozzi R, Luini A,etal.Twenty-year follow-up ofarandomized studycomparing breast-conserving surgery with radical mastectomy for early breast cancer. N Engl J Med. 2002;347(16):1227-32. https://doi. org/10.1056/NEJMoa020989

12. Tiezzi DG. Cirurgia conservadora no câncer de mama: Rev Bras Ginecol Obstet. 2007;29(8):428-34. http://dx.doi.org/10.1590/ S0100-72032007000800008

13. Gage I, Schnitt SJ, Nixon AJ, Silver B, Recht A, Troyan SL, et al. Pathologic margin involvement and the risk of recurrence in patients treated with breast-conserving therapy. Cancer. 1996;78(9):1921-8. https://doi.org/10.1002/(sici)10970142(19961101)78:9\%3C1921::aid-cncr12\%3E3.0.co;2-\#
14. Mirza NQ, Vlastos G, Meric F, Bucholz TA, Esnaola N, Singletary SE, et al. Predictors of locoregional recurrence among patients with early-stage breast cancer treated with breast-conserving therapy. Ann Surg Oncol. 2002;9(3):256-65. https://doi.org/10.1007/bf02573063

15. Vicini FA, Kestin L, Huang R, Martinez A. Does local recurrence affect the rate of distant metastases and survival in patients with early-stage breast carcinoma treated with breast-conserving therapy? Cancer. 2003;97(4):910-9. https:// doi.org/10.1002/cncr.11143

16. Kaufmann M, Morrow M, Von Minckwitz G, Harris JR. Locoregional treatment of primary breast cancer: consensus recommendations from an International Expert Panel. Cancer. 2010;116(5):1184-91. https://doi.org/10.1002/cncr.24874

17. Houssami N, Morrow M. Margins in breast conservation: a clinician's perspective and what the literature tells us. J Surg Oncol. 2014;110(1):2-7. https://doi.org/10.1002/jso.23594

18. Moran MS, Schnitt SJ, Giuliano AE, Harris JR, Khan SA, Horton J, et al. Society of Surgical Oncology-American Society for Radiation Oncology consensus guideline on margins for breastconserving surgery with whole-breast irradiation in stages I and II invasive breast cancer. Int J Radiat Oncol Biol Phys. 2014;88(3):553-64. https://doi.org/10.1016/j.ijrobp.2013.11.012

19. Waljee JF, Hu ES, Ubel PA, Smith DM, Newman LA, Aldeman AK. Effect of esthetic outcome after breast-conserving surgery on psychosocial functioning and quality of life. J Clin Oncol. 2008;26(20):3331-7. https://doi.org/10.1200/JCO.2007.13.1375

20. Valero MG, Golshan M. Management of the Axilla in Early Breast Cancer. Cancer Treat Res. 2018;173:39-52. https://doi. org/10.1007/978-3-319-70197-4_4

21. Veronesi U, Paganelli G, Viale G, Luini A, Zurrida S, Galimberti V, et al. Sentinel-lymph-node biopsy as a staging procedure in breast cancer: update of a randomised controlled study. Lancet Oncol. 2006;7(12):983-90. https://doi.org/10.1016/ S1470-2045(06)70947-0

22. Kim H, Cho J, Kwon SY, Kang SH. Biologic subtype is a more important prognostic factor than nodal involvement in patients with stages I and II breast carcinoma. Ann Surg Treat Res. 2016;90(1):1-9. https://doi.org/10.4174/astr.2016.90.1.1

23. Van Bogaert, L. J. Recent progress in the histological typing of human breast tumours. Diagn Histopathol. 1981;4(4):349-53.

24. Gurleyik G, Karagulle H, Eris E, Aker F, Ustaalioglu BO. Oncoplastic surgery; volume displacement techniques for breast conserving surgery in patients with breast cancer. Acta Chir Belg. 2017;117(3):169-75. https://doi.org/10.1080/00015458.2016.1272916

25. Kondov B, Isijanovska R, Milenkovikj Z, Petruveska G, Jovanovski-Srceva M, Bogdanovska-Todorovska $M$. et al. Impact of Size of the Tumour, Persistence of Estrogen Receptors, Progesterone Receptors, HER2Neu Receptors and Ki67 Values on Positivity of Axillary Lymph Nodes in Patients with Early Breast Cancer with Clinically Negative Axillary Examination. Open Access Maced J Med Sci. 2017;5(7):825-30. https://doi.org/10.3889/oamjms.2017.213 
26. Hieken TJ, Harrison J, Herreros J, Velasco JM. Correlating sonography, mammography, and pathology in the assessment of breast cancer size. Am J Surg. 2001;182(4):351-4. https://doi. org/10.1016/s0002-9610(01)00726-7

27. Davis PL, Staiger MJ, Harris KB, Ganott MA, Klementaviciene J, McCarty KS Jr., et al. Breast cancer measurements with magnetic resonance imaging, ultrasonography, and mammography. Breast Cancer Res Treat. 1996;37(1):1-9. https://doi.org/10.1007/bf01806626

28. Shoma A, Moutamed A, Ameen M, Abdelwahab A. Ultrasound for accurate measurement of invasive breast cancer tumor size. Breast J. 2006;12(3):252-6. https://doi.org/10.1111/j.1075122X.2006.00249.x

29. DiBiase SJ, K omarnicky LT, Schwartz GF, Xie Y, Mansfield $\mathrm{CM}$. The number of positive margins influences the outcome of women treated with breast preservation for early stage breast carcinoma. Cancer. 1998;82(11):2212-20.

30. Butler-Henderson K, Lee AH, Price RI, Waring K. Intraoperative assessment of margins in breast conserving therapy: a systematic review. Breast. 2014;23(2):112-9. https:// doi.org/10.1016/j.breast.2014.01.002 